\title{
The Targets and Challenges of Educational Systems for Teaching the Official Language
}

\author{
Neli Champuridze \\ Gori State University, Georgia
}

\begin{abstract}
Cultural preservation and protection of national minorities is essential for their full participation, achieving a sense of civic unity and gaining each other's confidence in the integrated cultural life. Intercultural dialogue is a precondition for peaceful coexistence for the representatives of different cultures being in constant contact.

Open, mutually respectful exchange of views between individuals and groups from different cultures lead to an in-depth understanding of differing ideology and practice. According to the educational objectives, teaching Georgian as a second language, takes into account the task of solving some particular problems, e. g. students should gain both linguistic and cultural information in order to get the ability of understanding different cultures, develop various types of relationship, particularly the abilities necessary to value and respect individual varieties. At the same time, they should be equipped with the sense of citizenship.

For the social integration of the ethnic minorities in Georgia, it's very important not only to teach them the State language, but also to give the knowledge of each other's traditions, values, lifestyles, etc.

Two different ethnic groups in one academic environment, show more interest towards different ethnic groups. As far as modern culture is focused on developing dynamic, open and creative abilities the positive achievements of other cultures are easily absorbed and they become a part of the culture. Though, they are subject to changes in the future.
\end{abstract}

\section{Introduction}

One of the most serious challenges for civil integration is the ignorance of the Georgian State Language that is the cause of holding up their fully fledged participation in the political, economical and public life of the country. One of the most important steps in this respect will be the implementation of the Georgian teaching programs in order to support the ethnic minorities to gain the high education. The essential objective of the Georgian teaching programs is to guarantee proper teaching of the Georgian State Language. It would contribute to producing and bringing up free individuals associated with the national and general human values. They would be able to become active members of the society and contribute to the implementation and development of the civil society in general.

According to the educational goals, teaching Georgian as the second language, considers resolution of particular problems, e. g. gaining both linguistic and cultural information in order to get the ability to understand different cultures, develop various types of relationship, in particular, the abilities necessary to value and respect individual varieties. Preserving and protecting ethnic minority cultures help us to fulfill the essential aspects of the program - the minorities fully fledged participation in the integrated cultural life, gaining each other's confidence and feeling of civil integrity.

It is a cornerstone for many Georgian citizens to learn the second language in order to achieve success on the academic level or in a career. It is well-known in the democratic countries that a removal of language barriers has got great importance for the social integration and development. That is why efficient teaching and learning of the second language is the subject of intensive research as well as the practical work.

\section{Methodology}

In 2011, under the framework of Civil Development Agency Project - Multilingual Trust Building Network, we carried out research in KvemoKartli and Samtskhe-Javakheti that revealed the fact of ignorance of each other's traditions among the ethnic groups there; while the cultural aspect is one of the most important components in the teaching programmes' efficiency in the bilingual schools.

In 2008, "The Concept for Minority Integration through Multilingual Education and Action Plan for 2009-2014" were elaborated with the support of the OSCE supreme commission for national minorities. 
In accordance with the Action Plan, the Georgian Education and Science Department began to support implementation and accomplishment of "Multilingual Teaching Programs".

Currently, revision and reformation of the teaching concepts, the organization of educational process and elaboration of the teaching methods are in progress. To be more precise, the interactive teaching methods are being implemented, the suitable teaching material is being elaborated and the teachers' training programmes are working, etc.

The priorities of educational system have been determined as follow: the teaching process should be focused on problem solving, development cooperative skills, establishment of democratic and civil society's principles.

It is possible to form a civil society through developing the critical thinking in the individuals. They will be able to express their ideas freely, to determine the problems they are facing, to find out the different means to solve the problems. At the same time, they will be able to select the strategies and plan the further steps. An individual is required to strive for actions that should ensure achievement of their targets.

All the above mentioned requires a special thinking as well as a sense of responsibility. In the 20-th century, all the experience accumulated in the struggle against the local or global problems made the scholars, politicians and public figures to revert to the importance of critical thinking. It is the responsibility of the system, and primarily of the school, to support the development of critical thinking. There are a lot of factors that influence the achievement of successful results, in particular, the formation of proper teaching programs, contents of educational systems, sophisticated textbooks, educational environment. However, the professional qualification and approach towards teaching as well as creativeness of teachers are considered to be the leading components.

The meaning implied under the term "critical thinking" has been developed in the works and expressions of many scholars since the oldest times. Critical thinking means curiosity, the use of proper strategies for enquiry, the methods of forming queries in the best way, searching answers for them. It contains not only fixing of the facts but also determining the causes and effects of them. On the one hand, critical thinking means polite skepticism, and on the other hand, it means having established individual standpoints [1].

The essence of critical thinking is not so difficult. It can be defined as caring about individual thinking. The value of it is also very easy to understand. We should do our best to care about our own thinking, as well as our private life, that means caring about improvement of our life, directing it to the positive targets.

The necessary prerequisites of the representatives of different cultures, who have constant relationship with each other, is the intercultural dialogue. There is no definition for it, that would be recognized worldwide. In November 2006 the Council of Europe presented the following definition: "An intercultural dialogue is a process, which means interchange of ideas between the individuals and groups who represent different cultures, based on openheartedness, mutual respect. It leads us to full recognition of various outlooks and practical work". [2]

According to the Universal Declaration of UNESCO on Cultural Diversity, in the culturally diverse societies it is vitally important to ensure the harmonious relationships and coexistence of the groups of people who have changeable and dynamic identities. An individual capable to contribute to effective development of the civil society is required to strive for the achievement of the targets, express personal ideas freely, determine problems and find a number of ways to solve them, select proper strategies and plan steps to be taken.

Intercultural astuteness is the behavioral dimension of competence for intercultural communication, that is an individual ability to achieve communication with the representatives of different cultures. This dimension consists of four components: informational skills, proper selfexpressing abilities, behavioral flexibility and management of interaction.

\section{Contribution to Knowledge}

The Georgian Teaching Program has been practiced for a year at the David Aghmashenebeli Georgian National Academy. Two Azeri and three Armenian students, citizens of Georgia, have been participating in the educational program. They passed National University Entrance exams and after the 
completion of the Georgian preparatory course, they will continue their studies at the NDA of Georgia. This one year preparatory course has been fully financed by the Georgian Government. The NDA offers them free service (free accommodation and food as well as all necessary conditions for studies and leisure are provided).

The NDA has created a precedent of serving different members of the society. This one year course of teaching the Georgian language to ethnic minorities of Georgia is carried out in the integrated academic and living conditions. In line with the Bologna Accords, the Georgian NDA teaching program is based on the system of continuity, human conceptions and creative approach to the teaching process. The research has been carried out at the NDA observing the students of the Georgian Language Teaching program. The students have been interviewed in depth on their intercultural and intellectual levels. The questionnaire has revealed that the ethnic groups show more interest towards each other's culture and history while being in the same academic environment. This interest enables them to be more extrovert and apt to adopt new features. The research has also demonstrated that the students show substantial interest to the origins of the Georgian, Armenian and Azeri languages, as well as to history, literature, ethnography, cultural traditions and religious beliefs

Thus, the "discoveries "of cultural similarities and differences have enabled us to build more intense communication between two ethnic groups. The students expressed their ideas freely and communicated with pleasure.

During the evaluation of the students (interview, observation) we have used intercultural knowledge, different components of intelligence and intercultural sensitivity scopes (self-assessment, self-monitoring, emphasis, openness, judgment, and social relaxation).

It is very important to support the development of intercultural consciousness in the society and, particularly, to raise the level of intercultural sensitivity with the help of properly selected educational programs. The success of intellectual development greatly depends on various factors, such as: properly selected teaching program, the right concept of education, well-elaborated text-books, educational environment, etc.

We consider that the existing educational environment plays an important role in the establishment of intellectual communications. The intercultural dialogue is a necessary precondition for establishing peaceful relationships between people of different cultures. For the social integration of ethnic minorities in Georgia, it's very important not only to teach them the State language, but also to give them the knowledge of each other's traditions, values, and lifestyles. We should also develop psychological acceptance towards them and in this regard, consider the ethnic diversity of a country on the level of civic consciousness.

In order to better realize the learning process of the second language the following aspects should be taken into consideration:

i) What does a person learn particularly while acquiring the knowledge of the second language? ( Linguistic aspect)

ii) What learning stages should a person pass while acquiring the knowledge of the second language? (Psychological aspect)

iii) What causes the fact that during the learning process some students are more successful than others? (Psychological aspect.)

There are no direct answers on the above questions since the issues are under the scientific discussions. The process of learning of the second language is multidisciplinary field of research (Linguistics, psychology.)

There are three ways of studying the second language:

1) Non-official learning in a natural context;

2) Official learning in the classroom;

3) Combined learning- learning both in the natural environment and classroom.

The modern directions of multilingual education consider teaching the language and transfer of knowledge of the subject too.

There are some advantages in the integrated method of teaching of the language and subject that are as follow:

1. While performing the integrated teaching of the language and subject simultaneously, there occur the actual learning. It increases learning motivation and ensures reaching the high linguistic competence.

2. The integrated teaching of the language and subject is effective in respect of time since in a particular period of time we can achieve the objectives set both by the teaching plans for the language and subject.

3. While teaching both the language and subject through the integrated style, the student has a chance of not only to learn 
the language but also practice it on the functional level.

"The official teaching of the second language has got great importance, though it doesn't mean only memorizing the grammatical structures and phrases by heart. During the process of teaching the teacher of the language should emphasize the lexical and semantic aspects of the language and not the phonological, morphological and syntactic structures" [3]. In the programs of multilingual teaching we should consider the difficulties connected with bilingualism, bilingual reading and high intercultural sensitivity.

While conducting multilingual programs, we should make a special focus on three main directions:

1) While planning a language lesson, the main importance should be given to the development of listening skills, as well as reading, verbal and writing skills.

2) While selecting the types of exercises we should emphasize visual aspects;

3) While selecting programs we should pay more attention to their contents, skills and topicality.

\section{Conclusions}

It is now evident that the teaching of the Georgian language to ethnic minorities should be carried out in the integrated academic environment, applying correctly selected multilingual teaching programs and proper strategies in order to achieve intercultural communication. This would be very beneficial for the ethnic minorities in Georgia to get fully integrated with the local society.

The program will contribute to intercultural knowledge, sensitivity and acquiring intercultural intelligence. The research scope involves four components: informational abilities, expression of individuality, flexibility in actions and interaction management. The ethnic groups will have opportunities to be more extrovert and apt to accept different ethnic cultures and traditions.

While conducting the multilingual educational programs, we should add the following items to obtaining knowledge of the subject: bilingualism, bilingual reading, high intercultural sensitivity and diversity of students. That is why it is vitally important to use a great variety of teaching methods in order to satisfy the necessities of diversities and at the same time comply with the teaching objectives. It is important to determine the contents of the teaching programs, the ways of putting them into life and determine the teaching methods for achieving high academic grades and results.

The above mentioned teaching pattern will impact on peace-building not only inside the country, but also throughout the region. Peace is the constant movement process and, therefore, needs to be developed in the constant, dynamic and democratic way. As far as modern culture is focused on developing dynamic, open and creative abilities he specific teaching framework (teaching different ethnic groups in one academic environment) will help us to solve the fundamental problems, such as: introduction of the democratic and civic principles, civil integration as well as establishment of tolerant consciousness.

\section{References}

[1] I. Chavchavadze. Thoughts. Tbilisi State University Publication, 1989, pp.24.

[2] "The Conception of National Minority Integration through Multilingual Teaching and the Framework of 2009-2014" Tbilisi 2008.

[3] L. Grigule, Multilingual Teaching Guidelines for Teachers, 2013, pp.82.

[4] "Checking the intercultural sensitivity in Georgian students". Bilingual Education, Tbilisi 2011\#5.

[5] G. Nizharadze, R. Mshvidobadze, T. Asatiani, T. Tsikhistavi. Conflicts. Tbilisi, 2010,

[6] www.diversity.ge/geo/resources. (Access date: 7 November 2014). 